\title{
Custom prefabrication of silicone tubes from urinary catheters for experimental peripheral nerve surgery
}

\author{
Aydin Saray MD
}

\begin{abstract}
A Saray. Custom prefabrication of silicone tubes from urinary catheters for experimental peripheral nerve surgery. Can J Plast Surg 2004;12(1):20-22.
\end{abstract}

The entubulation principle represents a neurobiological approach to nerve surgery in which the role of the surgeon is limited and intrinsic healing capabilities of the nerve play the primary role. Herein, a technique for fabricating custom-made silicone tubes from a silicone urinary catheter is described. Silicone tubes with varying size and dimensions can be tailored depending on the diameter of the silicone urinary catheter ( $14 \mathrm{~F}$ to $18 \mathrm{~F}$ ). Tubes crafted from silicone urinary catheters were used either as a nerve conduit to facilitate regeneration or as compressive nerve banding to simulate compressive neuropathy in the rat sciatic nerve. Custom-made silicone tubes have similar pros and cons to the commercially available silicone tubes regarding the capsule and foreign body reaction. It can be concluded that these cost effective tubes can be easily cut and used in experimental peripheral nerve surgery in developing countries where the cost of such materials becomes an important issue for the researchers.

Key Words: Nerve conduit; Peripheral nerve surgery; Silicone tube; Urinary catheter

\section{Fabrication sur mesure de tubes de silicone à partir de cathéters urinaires pour la neuro- biochirurgie expérimentale}

\begin{abstract}
En neurochirurgie, le principe de tubulisation est une approche neurobiologique dans le cadre de laquelle le rôle du chirurgien se trouve limité, au profit des capacités de guérison du nerf lui-même. On décrit ici une technique de fabrication de tubes de silicone sur mesure au moyen de cathéters urinaires. Il est possible de fabriquer des tubes de silicone de tailles et de dimensions diverses selon le diamètre du cathéter urinaire au départ (14F à 18 F). Ces tubes fabriqués au moyen de cathéters urinaires de silicone peuvent servir soit comme conduits pour promouvoir la régénérescence, soit comme dispositifs de cerclage pour stimuler la neuropathie de compression dans le nerf sciatique de rat. Ces tubulures fabriquées sur mesure présentent les mêmes avantages et inconvénients que les tubes de silicone vendus sur le marché pour ce qui est de l'encapsulation et de la réaction aux corps étrangers. En conclusion, nous jugeons ces tubes économiques et faciles à couper et à utiliser dans le contexte de la neurobiochirurgie expérimentale des nerfs périphériques dans les pays en voie de développement où le coût de ce type de fourniture est un sérieux obstacle à la recherche.
\end{abstract}

$\mathbf{Q}$ epair and reconstruction of peripheral nerve gaps are the R two most challenging problems in peripheral nerve surgery. Autogenous nerve grafting has been considered the best method for bridging nerve defects, but there are inherent shortcomings of this classic approach and results are not consistent. Recent advances in neurobiology and increasing knowledge of neurotropism have evoked interest in alternative techniques such as entubulation of nerve ends, which facilitates the accumulation of nerve growth factors inside the tube (1).

Silicone tubes have been used experimentally (2) and clinically (3-5) to enclose the proximal and distal ends of a transected nerve, leaving a short gap between the nerve ends. Re-exploration of the entubulized nerves revealed macroscopically normal nerve in the tube for short gaps (3). Furthermore, silicone tubes with diameters smaller than that of the intact nerve have been wrapped around the rat sciatic nerve for simulating nerve compression in rats and primates (6-8).

A previous paper by Al-Quattan (9) inspired us to investigate the possibility of fabricating custom-made silicone tubes from silicone urinary catheters. We were also prompted to devise such a custom-made silicone tube to overcome the financial drawbacks during the realization of our experiments on nerve compression and entubulation. This paper describes a technique of fabricating custom-made silicone tubes from a silicone urinary catheter with varying dimensions, which can be used in experimental peripheral nerve research.

\section{MATERIALS AND METHODS}

A silicone two-way urinary catheter (Silkomed, Rüsch Brilliant, Willy Rüsch AG, Germany) is commonly used in surgical specialties, especially in urology clinics for the drainage of urine (Figure 1). Silicone tubes with varying diameters and lengths can be tailored depending on the experimental design and the thickness of the nerve. The fabrication of a $20 \mathrm{~mm}$ long silicone conduit with an inner diameter of $3.4 \mathrm{~mm}$ (outer diameter $4 \mathrm{~mm}$ ) will be described here because such a conduit is suitable for the entubulation of a rat sciatic nerve gap without any compression. However, the same technique can be modified to fabricate larger or smaller tubes by selecting different sizes of silicone urinary catheters. The length of the tube can be adjusted according to the nerve gap because one

Department of Plastic and Reconstructive Surgery, Kirikkale University Medical School, Kirikkale, Turkey

Correspondence: Dr Aydin Saray, Konutkent-2, A1 Blok, No 57, Safranbolu Cad, Goynuk Sk, Cayyolu-06530, Ankara, Turkey.

Telephone 90-312-241-2374, fax 90-318-225-2819, e-mail asaray68@hotmail.com 


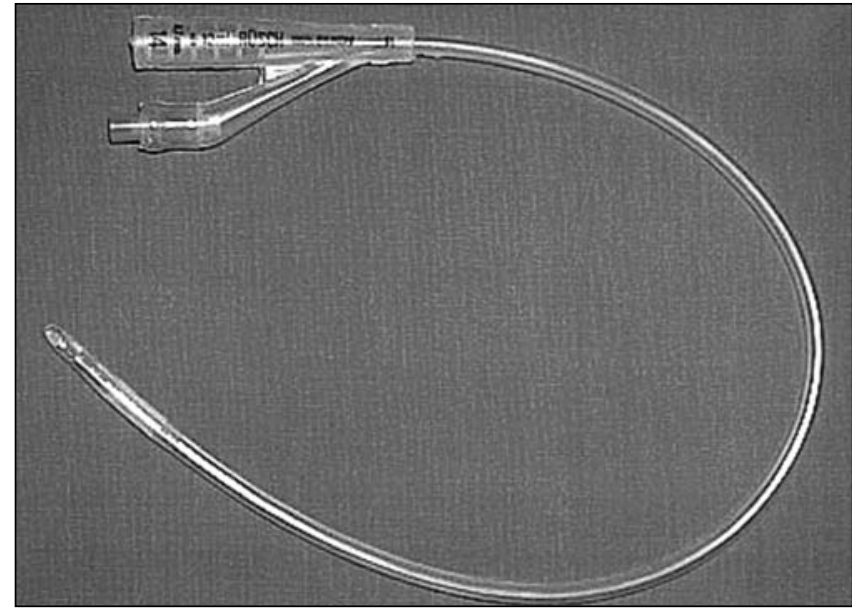

Figure 1) A silicone two-way urinary catheter, which is commonly used in surgical specialties

intact urinary catheter measures approximately $40 \mathrm{~cm}$, allowing fabrication of tubes with varying lengths.

Experimentation of the custom-made silicone tubes was done using magnifying loops $(4 \times)$ and a silicone urinary catheter $(14 \mathrm{~F})$. A $14 \mathrm{~F}$ silicone urinary catheter was laid on the operating table and a $14 \mathrm{~mm}$ segment of the tube was cut out easily by a scalpel. The resulting tube was $14 \mathrm{~mm}$ long with an internal diameter of $3.4 \mathrm{~mm}$ (Figure 2). The tube was then used to bridge a $10 \mathrm{~mm}$ gap in the rat sciatic nerve by inserting $2 \mathrm{~mm}$ of the proximal and distal nerve stumps into both ends of the tube. For studies on peripheral nerve compression, a silicone catheter for children with its diameter varying from $1 \mathrm{~mm}$ to $2 \mathrm{~mm}(6 \mathrm{~F}$ to $10 \mathrm{~F}$ ) can be used. The resulting tube had an internal diameter of $1.8 \mathrm{~mm}$ to $2.4 \mathrm{~mm}$. A silicone catheter with a diameter smaller than the nerve can be split longitudinally and wrapped round the nerve to mimic compressive neuropathy. The tubing edges can be then approximated with 6-0 monofilament polypropylene (Prolene, Ethicon, United Kingdom) sutures at both ends and at the middle.

\section{RESULTS}

Fabrication of tubes took approximately $45 \mathrm{~s}$. The fabricated tubes were durable against external pressure and successful nerve regeneration across the nerve gap was noted macroscopically and histologically. In all the experiments performed using this custom-made silicone tube, there was a thin capsule around the silicone tube that microscopically consisted of connective tissue, with thin walls and no signs of inflammation or granuloma after six months. The thin peritubular capsule showed connective tissue capsule with macrophage-like cells, abundant fibroblastic proliferation and diffuse lymphocytes, with collagen bundles and robust new vessel formations.

In the nerve compression studies, narrowing of the nerve along the silicone tube and swelling proximal and distal to the tube were gross findings. After removal of the custom-made silicone tube, the compressed nerve was found to be firm. Histological findings were in concert with the previous reports on experimental compression neuropathy.

\section{DISCUSSION}

Pioneering studies by Lundborg et al (1) showed that if a free space between two nerve stumps was created by a nerve chamber,

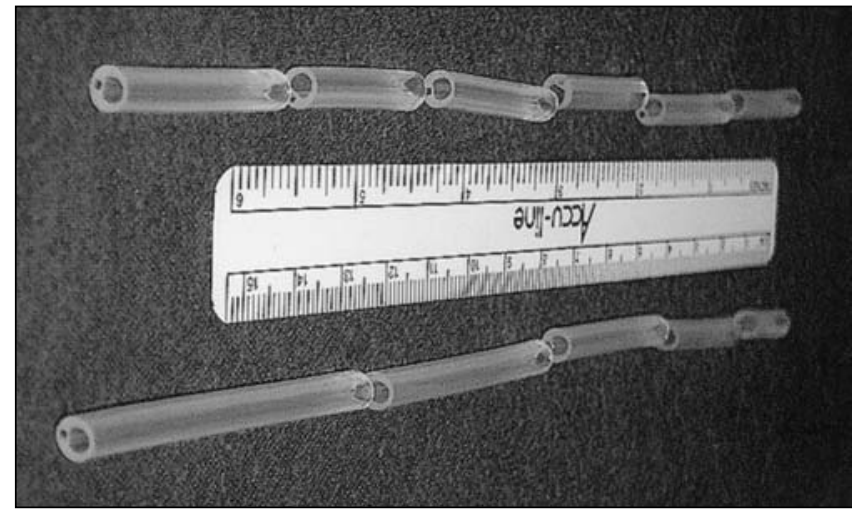

Figure 2) Custom-made tubes crafted from the silicone urinary catheter in varying lengths

the nerve fibers were able to find their way towards the distal stump. This and the following studies have culminated in the 'tubulization concept'. The tube functioned as a conduit for the regenerating nerve, provided longitudinal orientation for migrating cells and elongating axons, and insulated the growth process from the extraneural milieu. After a trial period in experimental studies, silicone tubes have been used in humans to bridge transected nerve trunks as an alternative to microsurgical coaptation techniques. Silicone was the choice of most authors in nerve entubulation research because it is relatively inert, nonreactive when in contact with the soft tissues and does not interfere with the regeneration process and secondary exploration of the repair site. Merle et al (10) were the first to use silicone nerve guides clinically, and reported successful nerve regeneration after reconstruction of peripheral nerves in three patients. Lundborg et al $(3,4,11)$ presented several prospective studies on the clinical use of silicone conduits in which motor and sensorial recovery in ulnar and median nerves was excellent. So far, clinical experience using silicone tubes is very limited (12). However, silicone tubing has several clinical problems, such as the necessity of a second operation for removal of the tube due to irritation, tube-related chronic nerve compression, inflammatory reaction that compromises neural function, and the impermeability of silicone polymer to oxygen and other nutrients.

Mackinnon et al $(6,13)$ and Dellon et al $(7)$ have previously crafted custom-made bands from silicone tubings and used these for experimental compression studies in primates and rats. Later on, commercially available silicone tubes were on the market, and Le Beau et al (14) used such tubes for the ultrastructural and morphometric analysis of nerve regeneration. However, Fields et al (15) created their nerve conduits from silicone thoracic catheters. As the final finesse, Al-Quattan (9) reported fabrication of silicone tubes with an inner diameter of $1.5 \mathrm{~mm}$ from a $0.12 \mathrm{~mm}$ thick silicone sheet for entubulation of the tibial nerve of the rat.

Custom fabrication of silicone tubes from silicone urinary catheters can be compared either with the manufactured silicone tubes, which are commercially available, or with the custom-made silicone tubes described by Al-Quattan (9). Custom-made silicone tubes have several advantages, including comparably lower costs, the fabrication of tubes 
with any desired length, readily made cylindrical shapes, and being readily available 'on the shelf'. The catheter-fabricated tubes can be also used to simulate chronic or acute nerve compression when they are used for nerves with equal or larger diameter. Also, with the goal of entubulation, it can be split and wrapped around the intact nerve, and nylon sutures can be placed into the silicone to close the tube if necessary. One drawback of the custom-made tube seems to be the limitation of diameter for any given urinary catheter but larger and wider catheters can be used to fabricate larger tubes for larger peripheral nerves. Besides, custom-made silicone tubes seem more suitable for compressive nerve banding studies because the elastomer membrane of the catheter is more durable when compared with commercially manufactured tubes.

Tubes fabricated from silicone sheets have disadvantages such as preparation time and the necessity of suturing the ends of the sheet to give a cylindrical shape. Al-Quattan (9) prefers to fabricate the tubes before the animal is anesthetized.

\section{REFERENCES}

1. Lundborg G, Dahlin LB, Danielsen N, et al. Nerve regeneration in silicone chambers: Influence of gap length and of distal stump components. Exp Neurol 1982;76:361-75.

2. Longo FM, Skaper SD, Manthorpe M, Williams LR, Lundborg G, Varon S. Neurotrophic activities accumulate in vivo within silicone nerve chambers. Brain Res 1983;261:109-17.

3. Lundborg G, Dahlin LB, Danielsen N. Ulnar nerve repair by the silicone chamber technique. Scand J Plast Reconstr Hand Surg 1991;25:79-82.

4. Lundborg G, Rosen B, Abrahamson SO, Dahlin L, Danielson N. Tubular repair of the median nerve in the human forearm. Preliminary findings. J Hand Surg [Br] 1994;19:273-6.

5. Braga-Silva J. The use of silicone tubing in the late repair of the median and ulnar nerves in the forearm. J Hand Surg [Br] 1999;24:703-6.

6. Mackinnon SE, Dellon AL, Hudson AR, Hunter DA. A primate model for chronic nerve compression. J Reconstr Microsurg 1985;1:185-94.

7. Dellon AL, Mackinnon SE, Seiler IV WA. Susceptibility of the diabetic nerve to chronic compression. Ann Plast Surg 1988;20:117-9.

8. Ress AM, Babovic S, Angel MF, Im MJ, Dellon AL, Manson PN.
Furthermore, the use of a 10-0 nylon suture to give the rectangular sheet a cylindrical tube shape can be time-consuming. In contrast, silicone tubes can be easily prepared before the experiment or the operation by cutting tubes out of the catheter, which is chosen before according to the diameter of the nerve.

\section{CONCLUSIONS}

Crafting silicone tubes from silicone urinary catheters can be a simple and versatile solution for experimental studies. However, these custom-made tubes also possess the common drawbacks of the commercially available silicone conduits in terms of fibrotic or inflammatory reaction and inadvertent compression of the nerve clinically. Thus, custom-made silicone tubes may serve as a tool for banding and entubulation of the nerves when manufactured 'ready-made' silicone tubes are not available or too expensive for the peripheral nerve researchers.

Free radical damage in acute nerve compression. Ann Plast Surg 1995;34:388-95.

9. Al-Quattan MM. Fabrication of silicone tubes in experimental nerve surgery. Can J Plast Surg 1995;3:54-5.

10. Merle M, Dellon AL, Campbell JN, Chang PS. Complications from silicone polymer entubulation of nerves. Microsurgery 1989;10:130-3.

11. Lundborg G, Rosen B, Abrahamson SO, Dahlin L, Danielsen N. Tubular repair of the median nerve in the human forearm: Early results from a prospective, randomized, clinical study. J Hand Surg [Am] 1997;22:99-106.

12. Meek MF, Coert JH. Clinical use of nerve conduits in peripheral nerve repair: Review of the literature. J Reconstr Microsurg 2002;18:97-109.

13. Mackinnon SE, O'Brien JP, Dellon AL, McLean AR, Hudson AR, Hunter DA. An assessment of the effects of internal neurolysis on a chronically compressed rat sciatic nerve. Plast Reconstr Surg 1988;81:251-6.

14. LeBeau JM, Ellisman MH, Powell HC. Ultrastructural and morphometric analysis of long-term peripheral nerve regeneration through silicone tubes. J Neurocytol 1988;17:161-72.

15. Fields RD, Le Beau JM, Longo FM, Ellisman MH. Nerve regeneration through artifical tubular implants. Prog Neurobiol 1989;33:87-144. 